\title{
GROWTH CHARACTERISTICS OF PERENNIAL RYEGRASS
}

\author{
W. F. Hunt, T. R. 0. FIELD \\ Grasslands Division, DSIR, Palmerston North
}

\begin{abstract}
A bstract
Mature perennial ryegrass plants in pastures persist through the asexual reproduction of the tiller. Leaves are initiated from the flanks of the tiller stem apex. Generally, two leaves arc growing on a tiller at any one time. New tiller buds may arise from the axils of mature leaves depending on environmental conditions. Flowering results from a physiological change at the stem apex, which then produces a seed head but no further leaves, eventually resulting in the tiller dying. This phenomenon and other environmental changes result in marked seasonal trends in ryegrass tiller densities. Leaf, tiller, and root production rates are sensitive to light and temperature where nutritional factors are not limiting. Tillering rates also change with stage of regrowth after defoliation. These factors are discussed with reference to their role in determining seasonal trends.
\end{abstract}

\section{INTRODUCTION}

TN ORDER to capitalize on the growth potential of a pasture species such as perennial ryegrass, it is necessary to understand both the basic structure of the plant and how the functional organs are affected by the stresses imposed in a pasture environment. This paper gives a brief morphological description of the perennial ryegrass plant, although more extensive descriptions may be found (Soper and Mitchell, 1956; Barnard, 1964; Langer, 1973). Growth responses of the plant organs obcerved in controlled environments and in the field are also described.

\section{MORPHOLOGY}

The structure of the vegetative plant is illustrated in Fig. 1, taken from Soper and Mitchell (1956). The germinated seed produces a coleoptile through which the first leaf emerges. Seminal roots emerging from the seed are fine and frequently branched compared with the first adventitious roots which emerge later from stem nodes. The fully developed plant produces a bulk of adventitious root of similar thickness and branching to seminal roots (P. S. Evans, pers. comm.). Successive orders of root branches are progressively thinner, and older adventitious roots are much more frequently branched than those depicted here. 


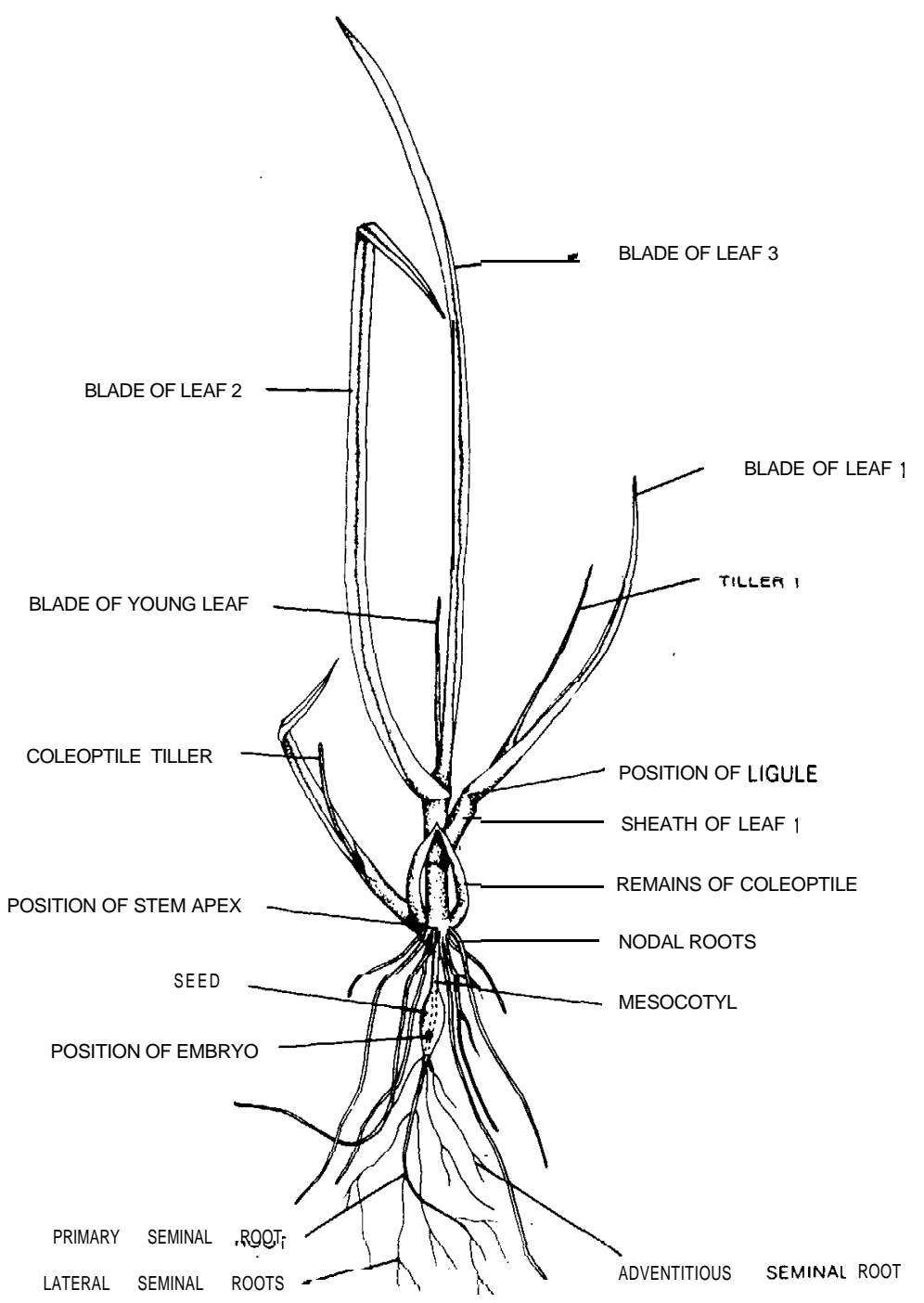

FIG. 1: Young perennial ryegrass plant (after Soper and Mitchell, 1956).

Leaves and adventitious roots arise from a compact stem as there is very little internode elongation in the vegetative plant. Hence the stem remains below cutting or grazing height and is able to produce new leaves and tiller buds after defoliation. Only 


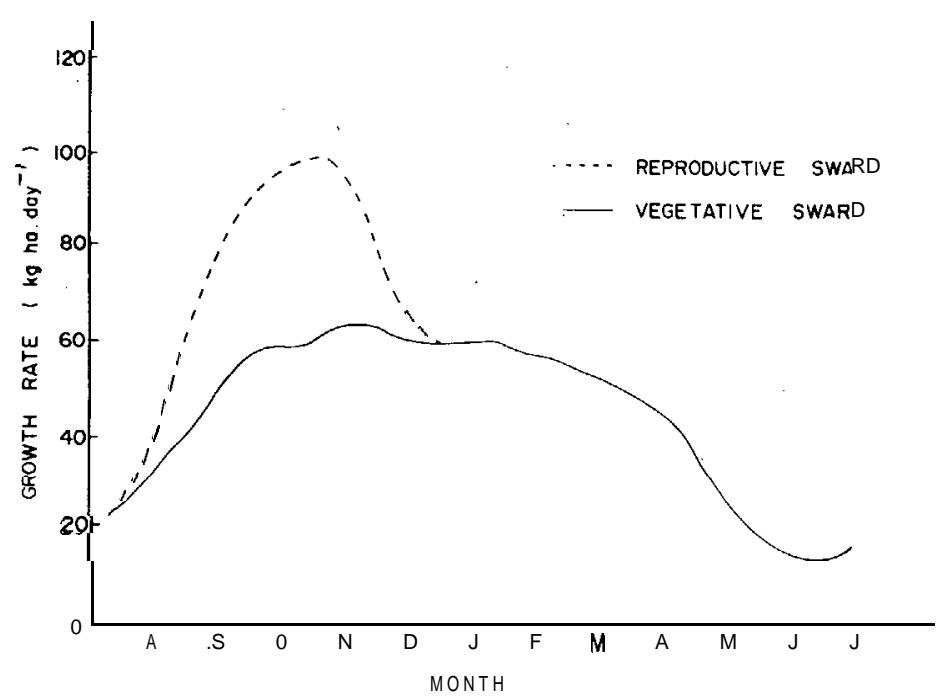

FIG. 2: Theoretical seasonal trends in perennial ryegrass growth rate for reproductive and vegetative swards assuming non-limiting water and nutrients.

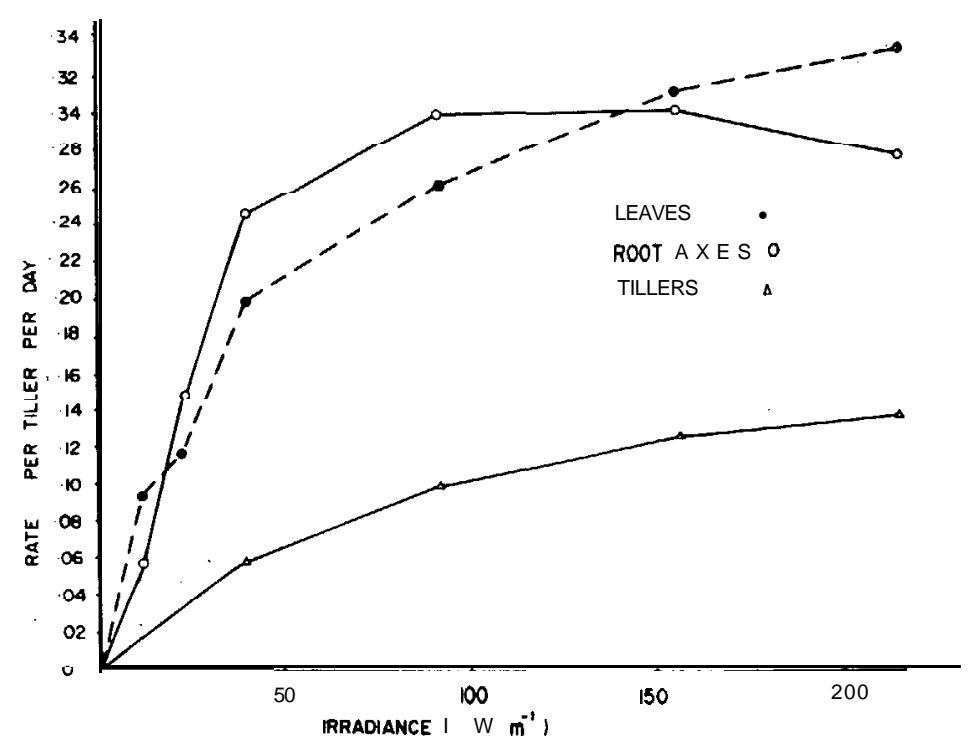

Fig. 3: Appearance rates of leaves, tillers and root axes for perennial ryegrass spaced plants grown at six light levels and constant temperoture $\left(20^{\circ} \mathrm{C}\right)$. 
two leaves actively grow on each tiller apex at any one time. The tip of one may have emerged through the middle of the encircling sheaths of the mature leaves while the other is only about $1 \mathrm{~cm}$ long.

The tiller is the primary growth unit of the mature plant, and has the same terminal apex structure as the main stem. Tiller buds are first formed in the axil of the main stem leaves and can grow out to produce additional leaves and tillers when conditions are favourable. The life span of individual tillers varies from a few weeks to more than a year, so the continued production of new tillers which replace senescent or reproductive tillers ensures the perenniality of the plant. Tiller density, if too low, could limit pasture growth potential by limiting the number of growing leaves. Where tiller densities are sufficient to induce tiller competition, differences in tiller density tend to be compensated for by differences in growth per tiller.

Tillers are induced to flower by low winter temperatures followed by increasing day length. About 6 weeks of cold (below about $10^{\circ} \mathrm{C}$ ) are required to fully vernalize perennial ryegrass (Evans, 1964). Reproductive tillers are incapable of further leaf or tiller initiation because floral parts are formed at the apex. The previously compact stem elongates during head emergence from the growth of internodes to project the spike above the leaf canopy. The spring period, when a high proportion of tillers are reproductive, is when maximum above-ground growth rates are observed. Growth is considerably faster than when all tillers are vegetative even under the same conditions of season and weather. This is illustrated in Fig. 2, in which the maximum growth rates of reproductive and vegetative swards have been calculated and compared. The growth rate calculations are based on controlled environment observations of responses to light and temperature, in combination with meteorological records for Palmerston North, and assume non-limiting moisture and nutrient conditions.

The curve for the reproductive sward agrees well with the expected pattern of maximum growth rate for perennial ryegrass under these conditions. The second curve predicts vegetative growth rate without the increased efficiency associated with reproduction. The difference between the curves in Fig. 2 arises from the more efficient utilization of light for growth by reproductive swards (Leafe et al., 1974). In addition, a greater proportion of growth occurs above ground during the reproductive- stage (Ryle, 1970). 


\section{CONTROLLED ENVIRONMENT RESPONSES}

The rates at which leaves, root axes, and tillers appear are determined by light and temperature where water and nutrient levels are non-limiting. Figure 3 illustrates how rates of organ production vary with light (12-hr day) at a constant temperature of $20^{\circ} \mathrm{C}$. In each case, the appearance rate increases rapidly with irradiance at low light levels, but much less rapidly with irradiance over $100 \mathrm{~W} / \mathrm{m}$ ' (about the same radiation for photosynthesis expected near Palmerston North on a late winter/early spring day). Similar curves have been obtained with plants grown at 7 , $10,17,30$ and $33^{\circ} \mathrm{C}$.

Curves fitted to such data (Fig. 3) provide an estimate of appearance rates at light saturation, allowing a comparison of organ appearance rates at different temperatures (Fig. 4). Light-saturated appearance rates for all organs show a fourfold linear increase with temperature over the 7 to $20^{\circ} \mathrm{C}$ range. Above $20^{\circ} \mathrm{C}$, organ appearance rates show no apparent response to temperature, but as organ weights decline, relative growth rates decrease by $33 \%$ between 20 and $33^{\circ} \mathrm{C}$.

The above data outlined the responses of organ production by perennial ryegrass to light and temperature. Net production in the field is also influenced by the rate of senescence of old leaves (Hunt, 1970, 1971) . Data have been drawn from the

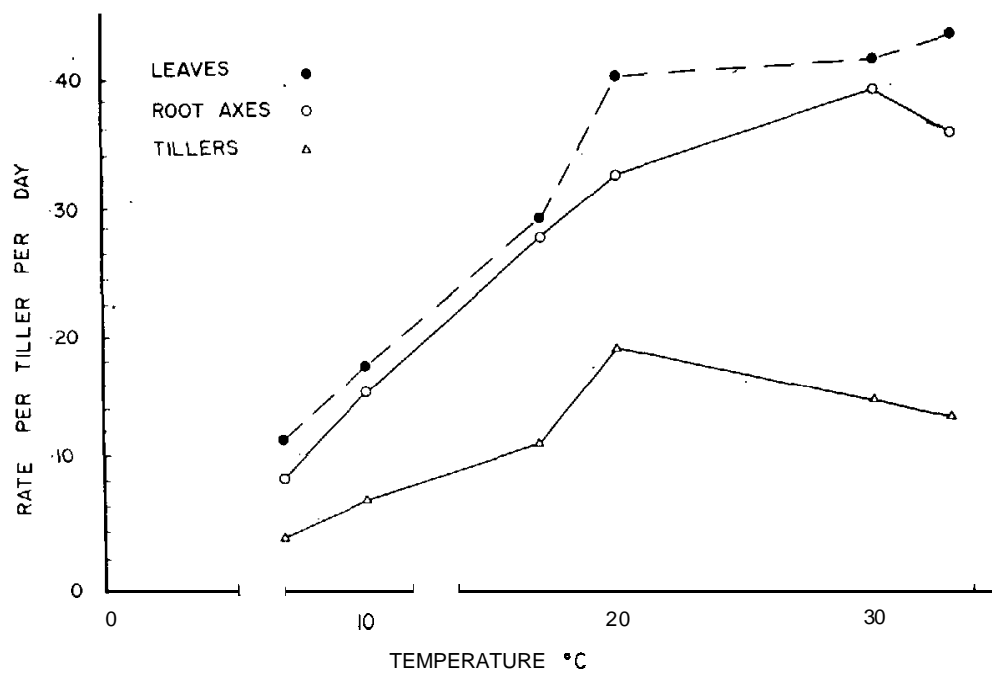

FIG. 4: Light-saturated appearance rutes for leaves, tillers and root axes for perennial ryegrass spaced plants grown at constant temperature. 
same controlled environment experiments to show the effects of light and temperature on leaf death. Leaf death has been expressed as a percentage of total leaf production, as this parameter remains constant in spaced plants once leaves begin to die.

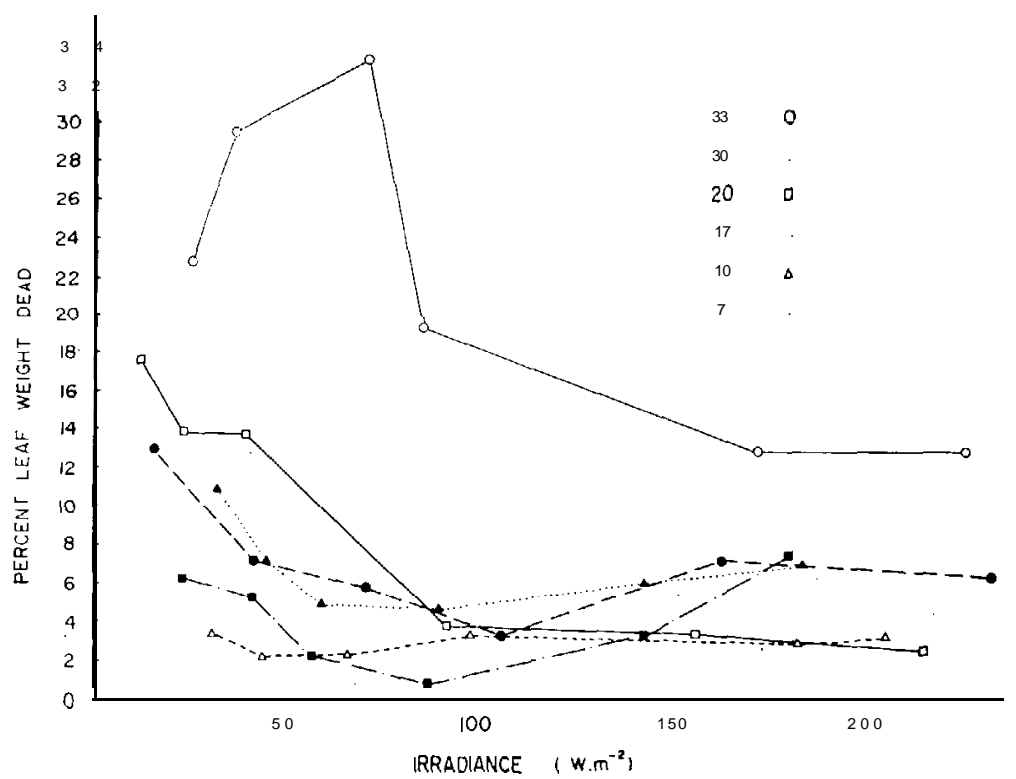

FIG. 5: Mean percentage leaf death on a weight basis for perennial ryegrass spaced plants grown at six light levels and six constant temperatures.

The data illustrated in Fig. 5 are mean values for several sequential harvests of exponentially growing plants. Generally, percentage leaf death is highest where irradiance levels are low, except at low temperatures $\left(7\right.$ and $\left.10^{\circ} \mathrm{C}\right)$, where no consistent relationship with light was observed. A feature of Fig. 5 is the relatively high percentage leaf death at $33^{\circ} \mathrm{C}$. The effect of temperature is illustrated in Fig. 6 as mean percentage leaf death over all light levels for both leaf number and leaf weight,

Leaf death-weight differences between temperature treatments clearly result from differences in the relative number of leaves that die. Leaf death appears minimal at 7 to $10^{\circ} \mathrm{c}$, and the relative weight loss is still less than $10 \%$ from 17 to $30^{\circ} \mathrm{C}$. A large increase in leaf death is observed at $33^{\circ} \mathrm{C}$, which is near the 


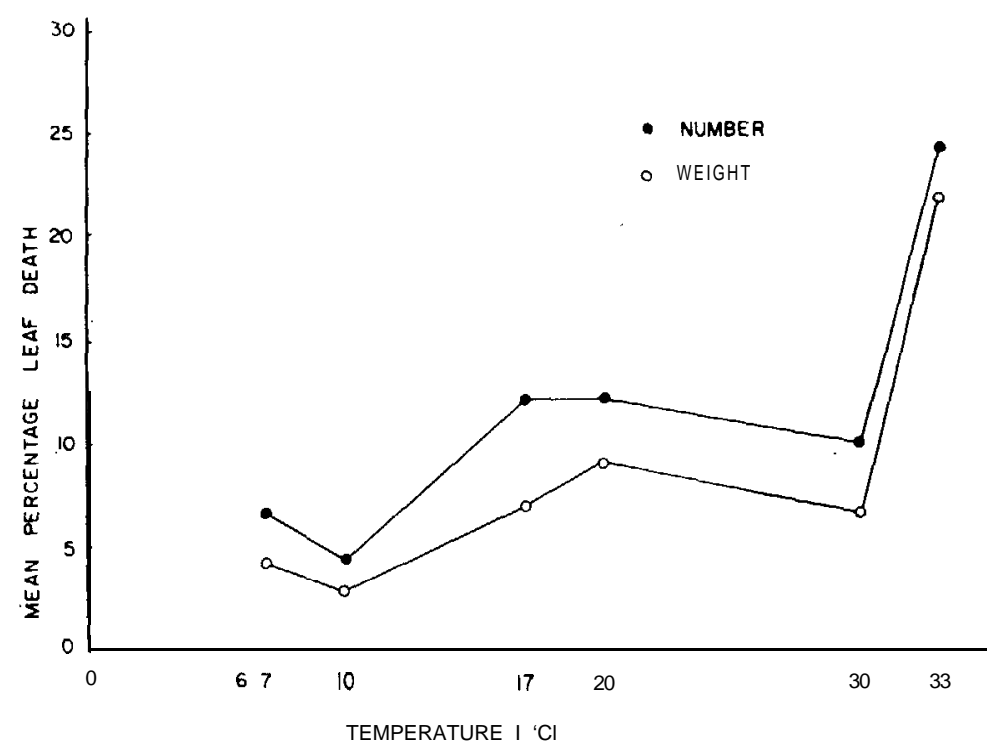

Fig. 6: Mean percentage leaf death over six light levels for perennial ryegrass spaced plants grown at six constant temperatures.

highest constant temperature tolerated by perennial ryegrass $(\mathrm{Cv}$. 'Grasslands Ruanui'). Seedlings grown at $35^{\circ} \mathrm{C}$ survived no longer than 2 weeks.

\section{GROWTH CHARACTERISTICS IN THE FIELD}

In addition to responses to light and temperature, the growth characteristics of ryegrass plants in the field can be modified by nutrient supplies, particularly nitrogen, Experiments at Gore (Harris et al., 1973) indicate that perennial ryegrass plants in mixed grass-clover swards suffer nitrogen stress at most times of the year. This results in reduced rates of tillering and growth compared with those obtained in controlled environment work.

Plants growing in the field also exhibit growth characteristics that are not easily attributable to the additional stresses of fluctuating supplies of water and nutrients. A major difference is that while spaced plants tend to tiller freely without competition, tillering in swards is often inhibited, particularly where the herbage. is long. The pattern in Fig. 7 was observed for 'Grasslands Nui' and Ruanui perennial ryegrass swards during early spring observations of tagged tiller samples. Appearance rates of leaves and tillers were calculated from differences in numbers of leaves and tillers between successive observations. 


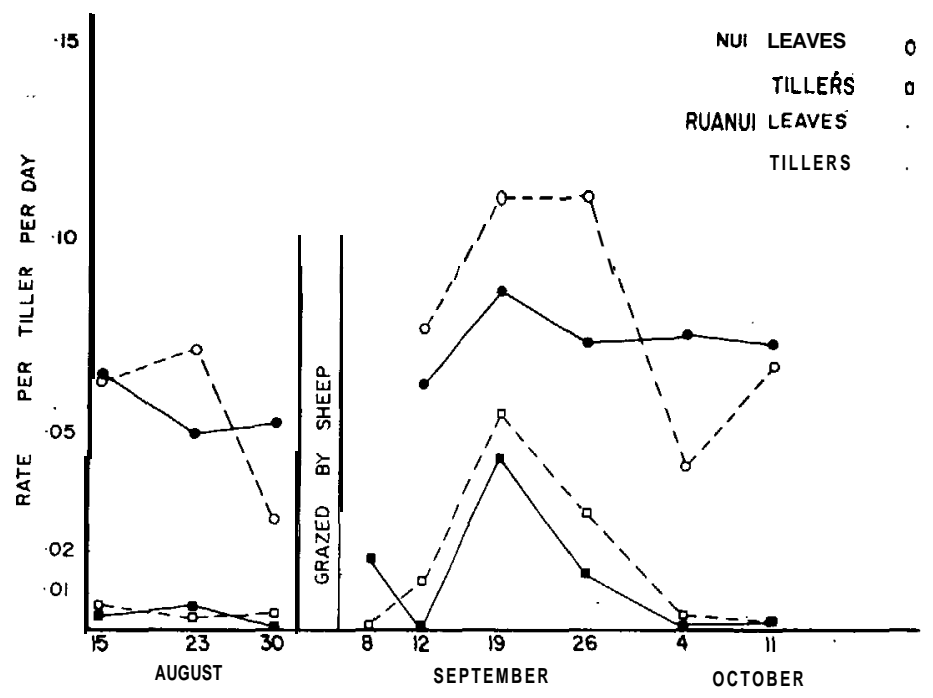

FIG. 7: Appearance rates of leaves and tillers on two perennial ryegrass cultivars during regrowth from defoliation.

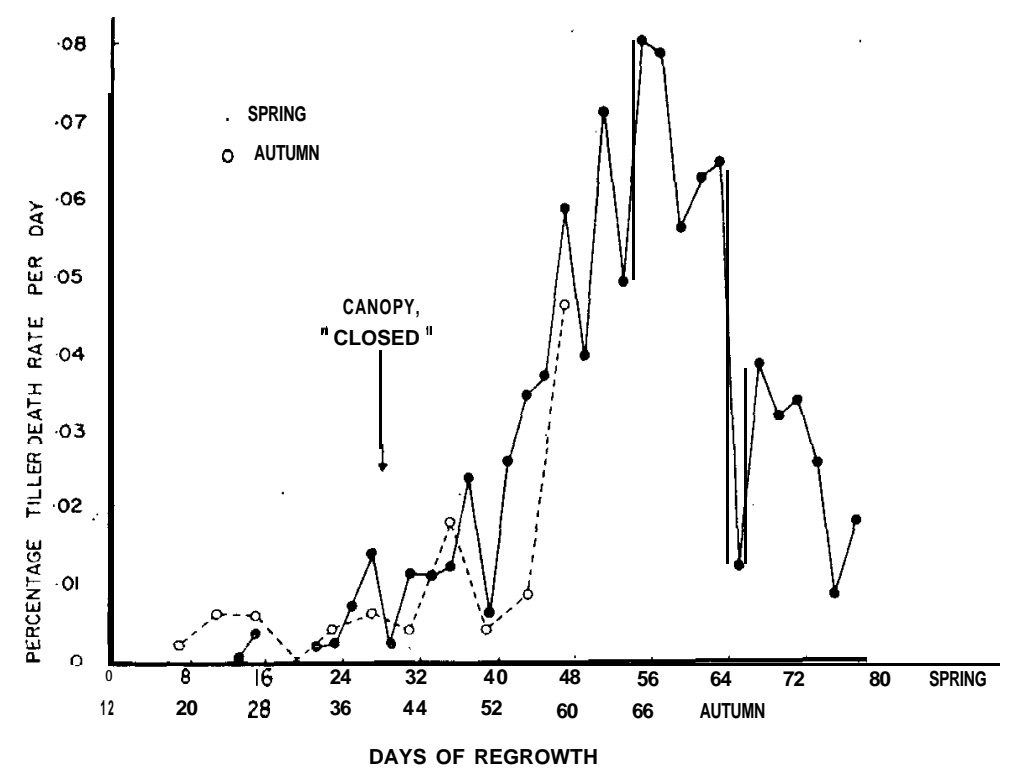

FIG. 8: Rate of death of perennial ryegrass tillers for two seasons in relation to the stage of $95 \%$ light interception in a mixed sward. 
Before grazing, when the herbage was long, leaf appearance rate per tiller averaged about one every 18 days, whereas tillering rate was close to zero. Following grazing, leaves appeared a little more frequently (about one leaf per tiller every 13 days), probably in response to seasonal increases in temperature and day length. Tillering remained at a low rate for 10 days after grazing before a short period of rapid tillering as tillers from buds "released" by grazing began to appear. Thereafter, tiller appearance rates declined to the low levels observed before grazing. A tillering flush, following defoliation is one mechanism leading to the commonly observed high tiller populations in frequently cut and continuously grazed swards, and low populations in infrequently cut or highyielding swards.

Another determinant of tiller density is the tiller death rate. which increases regardless of density if swards are undefoliated for long periods. However, field measurements indicate seasonal differences in the period following defoliation before tiller death rate becomes significant. The differences disappear when the data are plotted with reference to the time at which $95 \%$ light interception is achieved (Fig. 8), suggesting that the light regime within a sward is a major factor in determining tiller death rates. Tiller death rate declines after a stable population is reached.

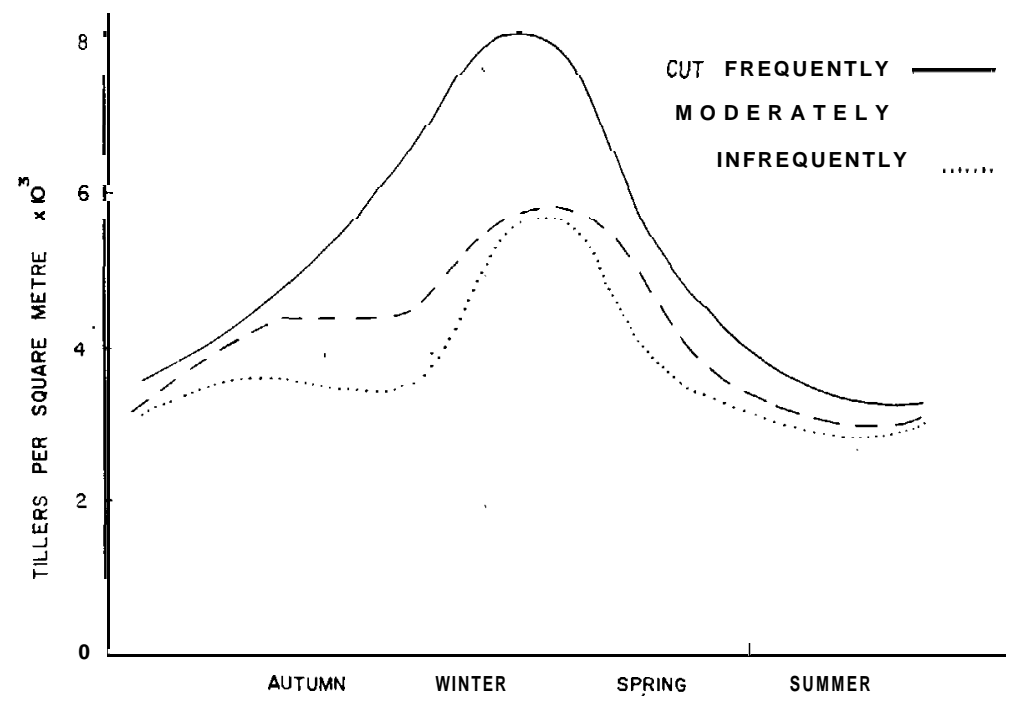

FIG. 9: Seasonal trends in the perennial ryegrass hybrid cultivar 'Grasslands Ariki' tiller densities under three management treatments. 
Thus, ryegrass tiller popuations are characteristically dynamic and capable of major changes in response to season and management. No individual tiller survives indefinitely, as those surviving inter-tiller competition are eventually induced to flower. Environmental, management, and physiological factors produce seasonal trends in tiller densities. Some examples are presented in Fig. 9 for a pasture based on 'Grasslands Ariki' ryegrass and 'Grasslands Huia' white clover with three cutting frequency treatments (2-3, 4-6 and 8-12 weeks) imposed over a 2- to 3-month period preceding measurements.

In each treatment, tiller densities peaked in late winter-early spring before a general decline that lasted through summer. The lowest densities occurred near the end of summer, possibly through accelerated tiller death when soil surface temperatures are high. Highest densities followed a gradual build-up in numbers over autumn and winter.

Cutting frequency appears to have a considerable influence over the autumn-winter period, when infrequently cut swards remained at relatively low densities. Frequently cut swards build up tiller numbers steadily, making midwinter the period when treatments differ most.

\section{CONCLUSIONS}

Ryegrass plants in pastures are in a dynamic state responding to seasonal and management influences. Seasonal influences largely determine the potential growth rate per tiller through their effect on leaf production. Flowering increases the above-ground growth potential so that growth is fastest in the spring. Management influences can modify seasonal trends in tiller densities through effects on the rates of tiller production and tiller death.

\section{REFERENCES}

Barnard, C., 1964. Grasses and Grasslands (Ed. C. Barnard). Macmillan, London. 269 pp.

Evans, L. T., 1964. In Grasses and Grasslands (Ed. C. Barnard). Macmillan, London, pp. 126-53.

Harris, A. J.; Brown, H. R.; Turner, J. D.; Johnson, J. M.; Ryan, D. L.; Hickey, M. J., 1973. N.Z. /l exp. Agric., I: 139-63.

Hunt, W. F., 1970. J. appl. Ecol., 7: 41-50. 1971. N.Z. Jl agric. Res., 14: 20818.

Langer, R. H. M., 1973. Pastures and Pasture Plants. (Ed. R. H. M. Langer). A. H. \& A. W. Reed, Wellington. 428 pp.

Leafe, E. L.; Stiles, W.; Dickensen, S. E., 1974. Proc. XII int. Grassld Congr.: 191-205.

Ryle, G.-J. A., 1970.1. appl. Ecol., 7: 217-27.

Soper, K.; Mitchell, K. J., 1956. N.Z. Il Sci. Technol., 37.4: 484-504. 